\title{
Introduction: Themes in Ancient Scholarship
}

This volume is a collection of papers presented at 'Ancient Scholarship: Scholastic Culture in the Hellenistic and Roman Eras', a conference funded by the British Academy and held at the University of Glasgow, UK on 27-28 April 2017. The purpose of this conference was to investigate scholastic culture in the Hellenistic and Roman eras, with a particular focus on ancient book and material culture as well as scholarship beyond Greek authors and the Greek language. Although ancient scholarship is a burgeoning field of study, a majority of investigations have focused primarily (and sometimes exclusively) on Greek scholarship and do not readily engage with the literature and languages of other cultures. ${ }^{1}$ Such studies are valuable contributions, but they do not represent the breadth of scholastic activity undertaken in antiquity. Accordingly, one of the major contributions of this work is the inclusion of multiple perspectives and its contributors engage not only with elements of Greek scholastic culture, but also bring Greek ideas into conversation with developing Latin scholarship (see chapters by Dickey, Nicholls, Marshall) and the perspective of a minority culture (i. e., Jewish authors) (see chapters by Hezser, Adams). This multicultural perspective is an important next step in the discussion of ancient scholarship and this volume provides a starting point for future inquiries.

In particular, the essays in this volume make important contributions and provide fresh insight into a few, specific areas. First, one of the fundamental aspects of this collection is the importance of book culture and the materiality of scholarship. Many works on ancient scholarship are limited to discussions of specific authors, texts, and ideas, but do not take into account the means by which scholarship is accomplished in ancient times. This singular focus is a clear oversight of the highly complex and interconnected nature of scholastic research. As a result, the importance of the intersection of text and scholar is highlighted in a number of chapters and is one of the theoretical underpinnings of this volume.

This framework is evident in the chapter by Stephanie Roussou, 'New Readings in the Text of Herodian'. Although Roussou provides fresh proposals for Herodian's

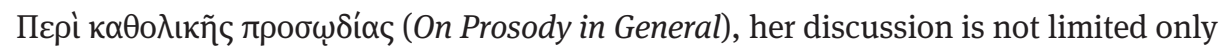
to the text as reconstructed. Rather, Roussou also evaluates newly-discovered manuscripts and discusses what they mean for our understanding of Herodian, his work and its reception, and the scholastic environment in which he wrote and in which

1 For traditional scholarship, see, e.g., Sandys (1903-1908); von Wilamowitz-Moellendorff (1921); Pfeiffer (1968). For more recent examples, see Dickey (2007); Montanari/Perrone (2009); Matthaios, et al. (2011); Montanari, et al. (2015). For engagement with other cultures, see Honigman (2003); Niehoff (2011).

Sean A. Adams, University of Glasgow

https://doi.org/10.1515/9783110660982-002 
his work was used. Here Roussou takes seriously the material nature of scholastic production and provides new and corrective insights to previous scholarship.

Fundamental to discussions of scholarship is the question of the scholar's access to texts. When thinking about scholarship in the Graeco-Roman world it is tempting to assume that scholars have ready access to the texts and materials necessary for their study. However, this assumption is rarely accurate, not only amongst those in communities and cultures that are not known for being intellectual hubs, but also amongst Greek and Latin elites. As can be seen from the laments of elite authors in the Roman era, even prominent scholars and writers have difficultly accessing texts. Moreover, the texts to which they do have access are not always in great condition or well edited (e.g., Galen, Peri Alupias 13, 19; Plutarch, Dem. 1.1-2). ${ }^{2}$ Christian and Jewish authors, although primarily focusing their intellectual energy on their authoritative religious texts, do not always have direct access to them. ${ }^{3}$ It might be that the texts that they do have are communally owned and so are not regularly or openly available (e.g., in a prayer house/synagogue/religious building). In addition, the texts that they do have may not be complete (i.e., a community might not have been able to acquire/afford a copy of all scriptural texts or every scroll of a large work). Similarly, when writers and scholars are travelling throughout the Greek, Roman, and Syrian worlds, something that is increasingly being recognised as a common phenomenon, ${ }^{4}$ the bulky and cumbersome nature of texts precludes their accompaniment. In these locations and situations, memorisation of texts plays a much more important role both in educational programmes as well as in scholarly discourse. ${ }^{5}$

At the same time, there is a strong, and indeed necessary, connection between texts and oral tradition. Not all scholarship is limited to texts, as can clearly be shown in some of the philosophical and rabbinic schools. ${ }^{6}$ In these communities, texts as well as received teachings form the basis of scholarly discussions, but they are also subsequently commented upon by later teachers, whose teachings, if warranted, become codified and part of the received tradition for subsequent generations. The intersection of oral and written teaching and the deep interplay between them through the centuries is understudied, primarily because we only have access to oral material if it was written down. In this instance, Classics scholars have much to gain from scholars of rabbinics and of later Judaism, whose key texts (i.e., Qumran

2 For discussions of personal libraries and access to texts, see, for example, Houston (2014).

3 Cf. Albl (1999); Albl (2016).

4 E.g., Tacoma (2016); Isayev (2017).

5 For the role of memorisation in Greek and Latin education, see, for example, Asmis (2001) 216 - 22. For the way that rabbis interpreted the lack of access to texts as an advantage, see y. Peah 2:6, 17a and the discussion by Hezser in this volume.

6 Oral tradition is evident in Greek philosophical communities (e.g., the disciples of Pythagoras) as well as rabbinic documents (e.g., Mishnah and Talmud). For a discussion of oral education and scholarship in the Qumran community, see Lemaire (2006); Brooke (2017) 21-26. Cf. Cooper (2007). 
scrolls, Mishnah, Tosefta, targumim) are codifications of collected wisdom of previous sages and represent one aspect of the process of textualisation.

When scholars do have access to texts, their location needs to be considered. In their contributions to this volume, Matthew Nicholls, Myrto Hatzimichali, and Gaëlle Coqueugniot address how literary fora, such as bookshops, libraries, and archives, influence ancient research practices, highlighting the issues and challenges of accessing and disseminating texts in the Graeco-Roman world.

The chapter by Myrto Hatzimichali, 'Circulation of Lexica in the Hellenistic and Early Imperial Period', teases out the movement and distribution of lexica and how these scholastic works (or parts of them) left the confines of libraries and became available to a growing number of individuals. Libraries, such as those at Alexandria, Pergamum, and Rome, still functioned as the hub of technical scholarly endeavours, and as Hatzimichali rightly notes, the lexica of Zopyrion, Dorotheus, and Pamphilus, the latter of which comprised ninety-five books, ${ }^{7}$ were unlikely to be found anywhere else. Similarly, other technical works were likely limited to major libraries (or maybe even just one library), but this did not stop portions, extracts, or epitomes of these works to leave the confines of the library and enjoy a distinct history of their own. ${ }^{8}$ These additional 'lives' of scholarly texts are insightful when considering scholastic processes and subsequent citations or references to major works.

Matthew Nicholls, in his chapter on "Bookish Places” in Imperial Rome: Bookshops and the Urban Landscape of Learning', highlights the blending of private and public space with regard to the book trade and intellectual discussions on available texts, moving the conversation of intellectual pursuits out of the standard institutions of learning and into the public sphere. Nicholls does not neglect the importance of libraries as institutes for study and discussion, but, though a detailed understanding of Rome's topography, he argues that neighbouring spaces with literary connections (e.g., book sellers along the Vicus Sandaliarius) could also be locations of dialogue and debate. The interaction of individuals within the texts discussed by Nicholls paints a picture of an urban landscape populated by a range of vested parties for whom the book trade and corresponding scholarship created a complex setting for social networking and public displays of erudition.

This larger discussion on access to books and composition lists is outworked in depth in the essay by Richard Marshall, 'Suetonius the Bibliographer'. Here Marshall investigates Suetonius' research and writing practices, specifically, his inclusion (and exclusion) of book titles in his Vitae Caesarum and De grammaticis et rhetoribus. These works, although informed by Suetonius' role as a bibliothecis, are not read through that lens. Rather, Marshall contrasts Suetonius' biographies, especially his restraint in cataloguing of the works of his subjects, to those of his predecessors, es-

7 The number is debated, ranging from 94/95 (Suda O 835; П 142) to 405 ( $\Delta$ 1140). Most scholars adopt 95.

8 E.g., Epitome of Pamphilus’ Glossai by Vestinus, surnamed Julius (Suda O 835). 
pecially Callimachus and his Pinakes. Taking into account both the geographical and societal situatedness of Suetonius (i.e., Rome), Marshall argues that Suetonius' work is a product of his location and that its author successfully exploited the malleable genre of biography.

Serena Ammirati investigates the nature of the scroll/codex and how material culture influenced text production. Ammirati, in 'For a Typology of the Ancient Latin Legal Book', outlines the development of the Latin legal book, arguing that a definitive typology did not emerge until the 5th century CE. Nevertheless, there are certain distinctive features (e.g., rubrics, capita, red ink, etc.) that show that the concept of the legal book was in the process of development. ${ }^{9}$

A second contribution is the importance of seeing a clear link between scholarship and education. Although there have been important works on education published recently, ${ }^{10}$ insufficient attention has been given to this association. At its most fundamental level, education provides knowledge of culture and the ability to access and interpret authoritative texts, such as Homer, Virgil, the New Testament, Hebrew Scriptures (i.e., Torah), etc. Indeed, one of the most important aspects of scholarship, as discussed in this volume, is its textuality. Knowledge of material, which regularly comes from texts, is a central component of what constitutes scholarly practice and the ability to handle and authoritatively interpret a text is what leads to a recognition of expertise. The concept of being an expert, as well as mastering a particular body of literature, linguistic phenomenon, or cultural perspective, is a prominent theme in many of the chapters.

Eleanor Dickey, in her chapter 'What Does a Linguistic Expert Know? The Conflict Between Analogy and Atticism?', argues that expertise is a prized possession within the scholarly world and the ability to handle rare words and constructions with ease gave the one who had attained this ability prestige in elite circles. Similarly, the ability to 'translate' literary texts and to communicate between linguistic codes is also recognised as falling within the purview of the expert and not something that was within the grasp of one lacking substantial education. The acquisition of expertise through extensive Greek or Hebrew paideia created bonds amongst its holders, and, as Catherine Hezser argues, this affiliations results in the creation of insider and outsider categories. The topics of expertise and the acquisition of skills that would be recognised by scholastic peers are also developed in the works of

9 A similar argument was advanced in the conference by Zachery Cole, who argued that the earliest Christian communities, although interested in texts, did not have a regulated means by which to ensure the fidelity and uniformity of texts (i.e., the absence of scriptoria). This lack of centralised control resulted in a diversity of manuscript forms and textual variants, but the widespread use of distinctive scribal habits (e.g., nomina sacra, codex format, readers' aids, etc.) militates against the view that there was no continuity in copying practices.

10 Marrou (1956); Bonner (1977); Morgan (1998); Cribiore (2001); Hezser (2001); Too (2001); Bloomer (2011). 
Adams (regarding translation) and Hatzimichali (regarding lexicography and linguistic specialisation).

A third contribution is the recognition that scholastic influence is not unidirectional. Although Greek practices influenced the scholarly habits and literary approaches of newly-conquered peoples, ${ }^{11}$ they in turn were also influenced by those whom they conquered (although possibly to a lesser extent). As a result, Greek scholastic culture needs to be understood within its wider historical and geographic contexts with an eye towards identifying distinct practices and shared perspectives. For instance, Gaëlle Coqueugniot argues in her chapter that the privileging of archival material in Greek historiography and its citation as a definitive source appears to develop as Greek authors encountered scholars from the East (e.g., Babylonians, Jews, Egyptians, etc.). Authors from these cultures, especially evident in the works of Berossus, Manetho, and Josephus, place a premium on archival records as the true source of distant times and cultural heritage. Indeed, the lack of Greek record-keeping was seen to be a detriment to their ability to write history with confidence and accuracy. ${ }^{12}$ Accordingly, Coqueugniot shows that there is a strong rise in archival use, indicating the adoption of foreign practices by Greek historians. Parallel scholarly development is also apparent in the widespread practice of commentary writing in which a lemma from a source text is commented on by an attentive reader(s). Such texts are not only found in Greek, but are also a prominent genre form in the Scrolls found at Qumran. ${ }^{13}$

In his chapter, 'Translating Texts: Contrasting Roman and Jewish Depictions of Literary Translations', Sean Adams undertakes a comparative work between Roman and Jewish interactions with Greek literary culture. For each group the importance of the source text, the direction of translation, and the intended purpose of the new work are key determiners of the nature of translation undertaken by the translator. Looking specifically at how literary translation is depicted in Roman and Jewish texts, Adams argues that many of the differences between Roman and Jewish authors result from the differences in power dynamics with Greek culture as well as the

11 In some instances Greek influence appears to be dominant, such as the development of $\zeta \eta \tau \eta \dot{\mu} \mu \tau \alpha$

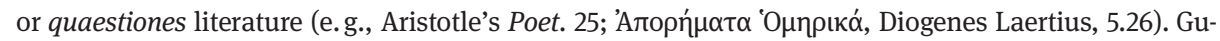
deman (1927). See also more recent investigations, though all have strong ties to Gudeman: Gartner

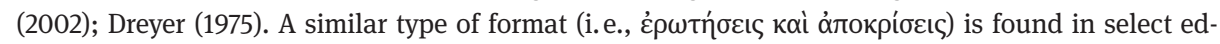
ucational texts (e.g., Stephani version of the Hermenumata). See Dickey (2012-2015), 1.26-27. This form of literature was adopted by the Jewish author Philo of Alexandria in his Questions and Answers on Genesis and Exodus and there is evidence of its inclusion in Demetrius the Chronographer's History (fr. 1.14; fr. 2.1-3; fr. 5.1).

12 Cf. Josephus, C. Ap. 1.19-22; Tertullian, Apol. 19.5-6.

13 E. g., Greek: Derveni Papyrus; Hipparchus of Nicaea's commentary on Aratus' Phaenomena; Anonymous Theaetetus Commentary (P.Berol.inv. 9782); Philo of Alexandria's Allegorical Commentaries; Hebrew pesharim (1Q14-1Q16; 3Q4; 4Q161-4Q173; 4Q252-4Q254; 5Q210). For a recent, comparative study of Hebrew and Greek commentary practices, see Hartog (2017). For a discussion of commentary scholia from a range of perspectives, including the ancient Near East, see Aufrère, et al. (2014). 
translator's relationship to the source text. By contrasting Roman and Jewish practices, Adams highlights distinctive elements and demonstrates how individuals from diverse but interacting cultures can differ in the ways in which they engage in the scholarly practice of literary translation.

In her chapter, 'Rabbis as Intellectuals in the Context of Graeco-Roman and Byzantine Christian Scholasticism', Catherine Hezser evaluates the ways that ancient Greeks and Romans marginalised Jewish Rabbis from intellectual discussions, seeing them as outside of the guild due to their communal focus and lack of Greek paideia; a picture that parallels the modern practice of isolating academic disciplines. Looking at the ways that Rabbis are depicted and presented in the surviving literature, Hezser argues that Rabbis saw themselves as scholars with circles of students who resembled Greek, Roman, and Christian scholars. These depictions, therefore, act as a counter-narrative to the dominant discourse and represent the claims of a minority culture attempting to navigate intellectual waters. At the same time, Hezser identifies parallel scholarly practices, particularly with regarding to encyclopaedism, reinforcing the interconnected nature of scholarship in antiquity.

In conclusion, a definition of scholarship in antiquity, including who does and does not engage in this pursuit, is of fundamental importance for how modern and ancient scholars create interpretive categories. Both ancients and moderns shape, and in many ways, presuppose the nature of 'scholarship' that is acceptable, recognised, or valid through the use of categories: a) by defining scholastic activity in a particular way (e.g., solitary versus communal; formal versus informal; intellectual versus practical); b) using a particular language (e.g., Greek or Latin versus Hebrew, Aramaic, Egyptian, etc.); c) written versus oral; d) being housed in particular geographic locations (e.g., Rome or Alexandria versus Jerusalem, Babylon, or other 'minor' city; Roman Empire versus Syria or Babylon); and e) with specific outputs (e.g., commentary versus dispute genres; encyclopaedia versus law codes; books or treatises versus embodied living). Such categorical exclusion or prioritisation are outdated and have failed to provide a robust and rounded picture of scholarly practices.

The chapters in this volume have made important contributions to weakening the above dichotomies. The materiality of scholastic practice (e.g., libraries, archives, scriptoria, manuscripts, etc.), the connection between education and scholarship, and the similarities and differences amongst scholars of different communities (i.e., Greek, Roman, Jewish, Egyptian) all open new avenues of exploration regarding ancient scholarship. The purpose of this volume is to begin the conversation, one that will (hopefully) be engaged by others. 